\title{
UNA TARDÍA DEFENSA \\ DE LA REFORMA TRIBUTARIA DE 1785: \\ LAS «CARTAS ECONÓMICAS» \\ DE RAMÓN MARÍA CAÑEDO
}

\author{
FERNANDO LÓPEZ CASTELLANO \\ Universidad de Granada
}

\section{RESUMEN}

Durante los primeros años del siglo XIX, son muchos los teóricos de relieve que defienden el sistema de contribuciones directas como el que más armoniza con el sistema de libertad a implantar, defensa más patente si cabe en los debates de las Cortes gaditanas. No obstante, un importante núcleo de autores niega la posibilidad de implantar un impuesto directo en sustitución del sistema de rentas vigente. Esta corriente crítica con la abolición se inicia con Vicente Alcalá Galiano, sigue su recorrido en los debates de Cortes y en las impugnaciones de Duaso, Pinilla y Plana al Decreto de 13 de septiembre de 1813, sobre Nuevo Plan de contribuciones públicas, y culmina con los escritos de Cañedo, en la década de 1820. Ramón M." Cañedo apostará por un sistema impositivo con predominio de impuestos indirectos. Apoyándose teóricamente en Smith, intentará adecuar sus principios tributarios al sistema de rentas reformado en 1785 . En su opinión, el impuesto indirecto es el que mejor se adapta a las condiciones sociales y materiales de la España de la época.

\section{ABSTRACT}

During the first years of XIX century, there were many outstanding authors who defended the direct tax system which fitted better with the new liberal Constitution. This posistion was even further reinforced in the «Cádiz Cortes». Nevertheless, some others important authors denied the possibility of setting up the new system in order to replace the old one. The later position began with Vicente Alcalá Galiano, continued with the debates in the Cortes de Cádiz and, later on, with the works of Duaso, Pinilla and Plana to critizise the Decreto (Bill) of September, 13, 
1813 on the New Public Taxes and it finished with several works by Cañedo in the second decade of the century. Ramón M.` Cañedo will defend a tax system based on indirect taxes. He will based his arguments on Adam Smith in order to fit his tax principles to the system which was set up in 1785. From his point of view, the indirect tax system was better adapted to the economic and social conditions in Spain.

\section{INTRODUCCIÓN}

La España del siglo XVIII contempla una dura pugna por sustituir el entramado tributario vigente por una contribución única de carácter directo. Son varios los proyectos emprendidos siguiendo la estela de Zabala - Ensenada, Cabarrús, Caamaño-, que buscan reemplazar el «sistema» de aluvión, compuesto principalmente de impuestos indirectos, que trababa los cambios (alcabalas y cientos) y gravaba el consumo de las principales subsistencias (millones y fiel medidor), pero el siglo finaliza sin que ninguno cristalice en la tan ansiada única. Sus años finales contemplan un continuo recurso a los medios extraordinarios, y en especial al uso del crédito, sin plantear reformas que requerían, inevitablemente, transformaciones en la economía y en la sociedad del Antiguo Régimen '.

Durante el período 1808 -1845 se suceden los intentos de implantar un sistema que acabara con la desigualdad de gravamen de personas y territorios $^{2}$, y en los años que van de 1808 a 1814 , la única contribución, ya transformada en directa, se convierte en sinónimo de reforma, no sólo tributaria sino también económica. El proceso se inicia con el Decreto emitido por la Junta Central el día 7 de agosto de 1809 , por el que se suprimen las rentas provinciales ${ }^{3}$, y culmina con el de las Cortes Generales y Extraordinarias de 13 de septiembre de 1813, mediante el que se establece una contribución di-

1 Vid. Tedde de Lorca (1988), p. 31; Fontana (1990), pp. 113-122; Lemeunier (1989), pp. 305-321; Pieper (1992) y Zafra (1990).

2 Para Fontana (1980), p. 31, todos estos intentos forman parte de un movimiento global que confluye en el sistema de 1845. Sobre el tema, vid. Artola (1986), Comín (1990 y 1996) y Fuentes Quintana (1990).

3 El Decreto se encuentra reproducido íntegramente en López-Juana Pinilla (1840-1848), tomo III, pp. 12-14. En él se expone un programa de profunda inspiración liberal, ligando intimamente sistema fiscal y desarrollo económico. Se califica a las rentas provinciales - alcabalas, cientos y millones, principalmente- de impuestos beligerantes con el desarrollo, dada su especial naturaleza y su peculiar sistema administrativo, y se propone un sistema tributario ideal sustentado en una serie de máximas, en las que se detecta el pensamiento de Smith. 
recta sobre las actividades productivas, repartida en función de la riqueza de los contribuyentes ${ }^{4}$.

Esta norma tiene escaso alcance práctico. El Decreto de 23 de junio de 1814 la declara sin efecto y restablece las rentas estancadas y provinciales al sistema de $1808^{5}$. Ello no obsta para que en el Decreto de 30 de mayo de 1817, sobre nuevo establecimiento del sistema de Real Hacienda, se supriman rentas provinciales y agregadas, contribuciones equivalentes de la Corona de Aragón, alcabalas enajenadas, contribución de paja y utensilios, extraordinaria de Frutos Civiles y se sustituyan por una contribución repartida proporcionalmente y sin excepción en todas las provincias ${ }^{6}$. Esta nueva reforma, conocida por el nombre del ministro de Hacienda, Martín de Garay, conduce al fracaso y entre 1820 y 1823 nadie se atreve a plantearla ni a recordar la contribución directa de las Cortes de Cádiz. La primera medida hacendística adoptada por la Regencia es el retorno al sistema anterior a $1817^{7}$.

Con todo, la «única» sigue estando presente, aunque con otro nombre, en las obras de Marcelino Calero y Esteban Pastor ${ }^{8}$. A partir de los años treinta, autores tan cualificados como Flórez Estrada, Torrente y Valle Santoro ${ }^{9}$ buscan sus fundamentos teóricos en el estudio de los sistemas fiscales de Francia e Inglaterra, abandonando la discusión emprendida en el siglo anterior. La obsolescencia de la única es un hecho y en la reforma de 1845 se acierta a ver la influencia del sistema de impuestos de producto surgido en Francia tras la revolución ${ }^{10}$. Esta reforma, pretendidamente más realista, se mostró a la postre insuficiente, al sustentarse en una contribución directa sobre la riqueza agraria y la propiedad inmueble, y en una contribución indirecta sobre los alimentos básicos ${ }^{11}$.

4 Decreto CCCIV: «Nuevo plan de contribuciones públicas de 13 de septiembre de 1813», en Colección de los Decretos y Ordenes que ban expedido las Cortes Generales y Extraordinarias desde su instalación (1813), tomo IV, pp. 229-237. El Decreto es fruto de un intenso debate que tiene lugar en las Cortes desde el día 6 de julio de 1813, fecha en que se presenta por la Comisión Extraordinaria de Hacienda el Informe sobre nuevo plan de contribuciones públicas, hasta los primeros días de septiembre del mismo año. Vid. López Castellano (1995).

s Decretos del Rey D. Fernando VII (1818), tomo I, pp. 84-89.

${ }^{6}$ Ibid., tomo IV, pp. 210-246.

Decreto de 9 de junio de 1823, en Decretos, ordenes y reglamentos expedidos por la $R e$ gencia del reino desde su instalación (1823), pp. 28-33. El decreto deroga todas las contribuciones establecidas por el gobierno revolucionario y restablece las rentas provinciales y estancadas.

${ }^{8}$ Fontana (1972), pp. 116-117.

9 Fontana (1972), pp. 118-119.

${ }^{10}$ Fuentes Quintana, E.: Prólogo a Estapé (1971), p. XVIII.

1 Siguen persistiendo estancos y aduanas y se sustituyen las rentas prón de inmuebles, culvalentes en Aragón, paja y utensilios y frutos civiles, por una «contribución de inmuebles, cul- 
Fontana califica de «asombrosa supervivencia de un mito» a ese persistente empeño de sustituir el sistema tributario del Antiguo Régimen por la única contribución. En ese largo período de tiempo que abarca cerca de un siglo — «desde la exposición que Zabala elevó a Felipe V en 1732 hasta el fracaso de la reforma de Garay en 1820»12-, multitud de escritos de «arbitristas más o menos intencionados» buscan el tributo o tributos susceptibles de subrogarse en el sistema de impuestos indirectos imperante. El objeto de este modesto trabajo es analizar la otra cara del mito, esto es, la defensa de rentas provinciales frente a contribución directa. El estudio se inicia con la reforma de Lerena de 1785 , cuya defensa dará lugar a una corriente crítica con la contribución directa. En ésta se inscriben el Informe emitido por V. Alcalá Galiano, sobre el Decreto de 1809, y las objeciones de Duaso, Plana y Pinilla al plan de nuevas contribuciones establecido por Decreto de 13 de septiembre de 1813. Desde la atalaya de 1826, y con el apoyo teórico de Smith, Ramón María Cañedo va a retomar la vieja polémica, impugnando el impuesto directo y defendiendo el sistema establecido en 1785 . En este sentido se aprecia un cambio de rumbo con relación a sus escritos de 1814 y 1816 en los que rememoraba los argumentos que esbozara Zabala en su exposición.

\section{LA REFORMA DE LERENA: ¿REALISMO FISCAL O RESPETO AL ORDEN ESTAMENTAL?}

La reforma tributaria acometida por el ministro Lerena en 1785 , tan celebrada por Alcalá Galiano, Gallard y Alonso Ortiz, entre los contemporáneos ${ }^{13}$, se ha valorado de forma muy positiva en la actualidad, como un firme intento de eliminar los defectos del sistema de rentas provinciales y una nueva concepción del reparto de la carga tributaria, además de una vía de fomento de las manufacturas nacionales, con la rebaja de los tipos de

tivo y ganadería»; un «subsidio industrial y de comercio»; un «impuesto sobre el consumo de especies determinadas»; una «contribución sobre los inquilinatos», que no llegó a implantarse, y «el derecho de hipotecas». Fontana (1980), pp. 43-46.

12 Fontana (1972), p. 111.

13 Sobre la publicación, «con subvención del Estado», de la memoria de Diego Gallard y la escrita por Vicente Alcalá Galiano, asesor de Floridablanca, y Vicente Matecón de Arce, por la Sociedad Económica de Segovia, a propósito de la reforma. Vid. Carrera Pujal (1943-47), tomo IV, pp. 340-343. Cabarrús (s.f., Carta III), pp. 170-171 criticará la reforma y referirá que: siempre me bonraré de baber tenido por enemigo al estúpido ministro que autorizó este incomprensible monumento de ignorancia y de ferosidad, y al escritor cien veces más vil y menos disculpable, que tuvo el descaro de elogiarle. 
gravamen y la modificación del sistema de percepción que propugnaba ${ }^{14}$. También se ha escrito que respondió a un alto grado de realismo fiscal al buscar, fundamentalmente, sanear y simplificar la administración de rentas ${ }^{15}$. Más recientemente se la ha tildado de «sistema» coherente con el marco económico, social y político de la España de finales del XVIII ${ }^{16}$, y a la contribución de «Frutos Civiles», principal novedad del nuevo «sistema», de «genuína reforma ilustrada» y de «precedente institucional» de la reforma de 1845 , lo que constituiría un punto de enlace entre los hacendistas ilustrados y modernos ${ }^{17}$. No todo son juicios positivos. También se ha aducido que el éxito de la reforma estribó en que no cuestionó el sistema fiscal y político del Antiguo Régimen ${ }^{18}$. Desde esta óptica, puede afirmarse que nació como reacción del poder público ante las propuestas de implantación de la contribución única.

El origen de la reforma se encuentra en el Dictamen de Floridablanca ${ }^{19}$, redactado como respuesta a la proposición que le remitiera el conde de Gauza, con fecha del 12 de diciembre de 1783, en la que le adjuntaba la «Memoria para la extinción de la Deuda nacional y arreglo de contribuciones» de Cabarrús. En su contestación a Gauza, Floridablanca descalificará el proyecto de Cabarrús emitiendo el siguiente juicio:

una general de esta naturaleza podría ser muy aventurada en su ejecución y en sus efectos y exponernos, si no preceden otros conocimientos, cálculos y experiencias a una convulsión espantosa en el orden económico y en todo lo que de él depende e interesa al rey y a la nación ${ }^{20}$.

${ }^{14}$ Vid. Fuentes Quintana (1964), pp. 23-25.

15 Matilla Tascón (1947), p. 131.

1h Llombart (1994), pp. 11-39, y García-Cuenca Ariati (1991), pp. 59-74, y (1990), pp. 27-34

${ }^{17}$ Hernández Andreu (1993), pp. 647-654.

${ }^{18}$ Moral Ruiz (1990), pp. 37-38.

14 Floridablanca, conde de: Dictamen del señor... sobre el modo de aumentar las rentas provinciales (15-5-1784), Archivo Histórico Nacional, Estado, leg. 238, núm. 2 (1784). En dicho legajo se encuentra el borrador del Dictamen y un manuscrito en el que puede leerse: Según los principios establecidos en este dictamen se expidió el Decreto de 29 de junio de 1785; la instrucción provisional de 21 de septiembre del mismo año; el reglamento de 14 de diciembre del mismo año; y el método para la formación de los nuevos encabezamientos de los pueblos. También se encuentra un papel sin fecha en el que se coteja la antigua administración de rentas con la que se introduce por el reglamento de 14 de diciembre de 1785 , y se demuestra por este sencillo medio cual sea más recta, más útil y más igual como lo desea S.M. en su citado Real Decreto de 29 de junio del propio año. El Dictamen de Floridablanca de 15-5-1784 se encuentra reproducido en Anes (1974), pp. 31-45. Para el profesor Artola (1982), p. 331, Floridablanca transforma el plan de Cabarrús en la contribución de Frutos civiles. El profesor Fuentes Quintana (1964), p. 22 , ha descrito esa secuencia: única contribución-plan de Cabarrús-Dictamen de Floridablanca-Reforma de 1785 .

${ }^{20}$ Anes (1974), p. 31. Sobre el tema, vid. Matilla Tascón (1947), p. 128. 
Así, pues, negará toda posibilidad de implantar una contribución única, por las dificultades que planteaba su realización - toda novedad es odiosa- y porque causaria un trastorno general en la monarquia, con riesgo evidente de arruinarla $^{21}$. La concepción patrimonial de la Hacienda de este tardío mercantilista, como lo ha definido el profesor Elorza, lo lleva a considerar el impuesto como «marca de soberanía», que se justifica por el Estado en sí mis$\mathrm{mo}^{22}$. Para Floridablanca, la Real Hacienda no es otra cosa que el rédito, rentas o frutos que produce la grande heredad de la monarquia ${ }^{23}$. El fin de toda política es el fortalecimiento del Estado, de ahí que apueste por la continuación del proceso de concentración del poder político y de racionalización de su ejercicio emprendido por los monarcas precedentes.

La propuesta de Floridablanca es un fiel reflejo de las reformas absolutistas: cubrir las crecientes necesidades financieras del Estado sin alterar las bases del sistema fiscal ${ }^{24}$. De ahí que se centrara en la reorganización del sistema de rentas para aumentar la recaudación y en un tímido intento de penetrar en la riqueza territorial, y no en transformaciones en profundidad de la estructura tributaria. Su plan se concretará en la reducción de derechos para corregir el efecto acumulativo de la alcabala ${ }^{25}$ y en el establecimiento de una contribución sobre los frutos civiles ${ }^{26}$.

${ }^{21}$ Floridablanca (1982), p. 229. En este sentido, advertirá acerca de la negativa experiencia que supuso la exacción del catastro en Cataluña, donde hubo que implantar el tributo personal para completar el equivalente y aliviar el gravamen de las tierras y propiedades, lo que obligó a realizar múltiples operaciones. A su juicio, el crecimiento de Aragón había que buscarlo en la petrificación de la cuota de su equivalente, inalterada, a pesar de la variación de los tiempos y, con ellos, del aumento del tráfico general y la población, de la abundancia y menor estimación del dinero $y$, por consecuencia, del mayor valor de los frutos.

22 Elorza (1968a), p. 565.

${ }^{23}$ Floridablanca (1982), p. 189.

${ }^{24}$ Sobre sus conocimientos científicos, León de Arroyal (1971) tenía serias dudas: El Conde de Floridablanca, que entendia tanto de economía politica como de castrar ratones... Como señala Fontana (1987), pp. 157-168, la política del reformismo absolutista, que no ilustrado, estaba dominada por la preocupación de aumentar los ingresos del estado, utilizando cualquier medio que le llevase a ello. Gerloff (1961), tomo II, p. 264, añade una interesante explicación política al fenómeno: Cuando la intervención fiscal en la economia privada es más difícil, ya por el monto de la carga en si, ya a causa de privilegios impositivos, entonces es mayor el uso de impuestos indirectos, particularmente al aumentar mucho la demanda financiera.

${ }_{25}$ A tal fin recomendaba proceder de manera progresiva a la exención de alcabalas y cientos en las ventas de géneros fabricados en el Reino, sin distinción de primeras o segundas ventas, comenzando por los que se traficasen y llevasen dentro y fuera de él a ferias y mercados y dando este impulso a las fábricas y al comercio interno y externo. Floridablanca, conde de: «Dictamen (...) 15 de mayo de 1784», en Anes (1974), pp. 36 y 40.

26 Consistente en gravar un tanto por ciento sobre los frutos y réditos civiles que perciben los dueños o interesados en ellos con proporción a la calidad de cada rédito y al menor o mayor gravamen que actualmente sufren. Ibid. 
Lerena asumirá estas propuestas y se inclinará hacia los aspectos administrativos de la Hacienda. El ministro, que se autodefine como apasionado del orden y economía en la Real Hacienda, reconocerá que sus esfuerzos se dirigían a metodizar la gestión de las rentas provinciales para lograr guardar las reglas de equidad y de justicia. Lerena sólo tuvo un objetivo: reformar la gestión de las rentas con el fin de aumentar su rendimiento. A su juicio, la rebaja de los derechos de alcabalas y millones hacía preciso encontrar un arbitrio que no fuese gravoso al pueblo, y que produjese lo preciso para cubrir el déficit y pagar la deuda nacional, por lo que proponía la imposición de frutos civiles como la única que no se opone á los progresos de la riqueza nacional ${ }^{27}$.

Estas ideas se verán reflejadas en el Decreto de 29 de junio de 1785 . En éste se exponía que, ante las crecientes necesidades derivadas del gran volumen de gastos y el continuo aumento de la deuda, se había optado por reformar ó economizar dispendios en todas clases y ramos, evitando por abora nuevos impuestos, y arreglar una mas recta, mas útil y mas igual administración de las rentas de la Corona que la que se ba tenido hasta aqui ${ }^{28}$. El arreglo consistía en la extensión del encabezamiento para las rentas provinciales ${ }^{29} \mathrm{y}$ en el establecimiento de la contribución de frutos civiles, para lo que se ordenaba realizar una relación de los hacendados forasteros y habitantes del pueblo, con el detalle de la calidad y, extensión de sus fincas, su forma de explotación y la cantidad cobrada en concepto de arrendamiento si fuesen arrendadas ${ }^{30}$.

Esta contribución, adoptada básicamente para compensar el vacío que habría de dejar el descenso de los tipos de gravamen en las rentas provin-

${ }^{27}$ Lerena (1845), p. 61.

28 «Real Decreto que el Rey se sirvió comunicar al superintendente general de la Real Hacienda, para arreglar por provincias y partidos las rentas provinciales en la forma que se expresa» (29-06-1785), en López-Juana Pinilla (1840-1848), tomos II, pp. 645-647, y III, pp. 476-478.

29 «Real Decreto que el Rey se sirvió comunicar al superintendente general...», en LópezJuana Pinilla (1840-1848), tomo II, pp. 645-646. Se advertía que en los pueblos encabezados debían contribuir los propietarios de bienes, tierras o derechos reales o jurisdiccionales, por las rentas que disfrutaran y que en los pueblos administrados debía regularse la alcabala de tal manera que no entorpeciera el progreso de la industria, fábricas y comercio.

${ }^{30}$ «Instruccion provisional que observarán los directores generales de rentas, intendentes, administradores y demás empleados de la Real Hacienda, en lo que respectivamente les toque y se les encargue para la ejecución del decreto antecedente, mientras la experiencia acredite si conviene variar o no alguna de sus reglas (21-9-1785)», en López-Juana Pinilla (1840-1848), tomo II, pp. 648-657, y tomo III, pp. 479-488. La cita, en tomo II, pp. 648-649. Por el Reglamento de 14 de diciembre de 1785 se fijaban las nuevas cuotas de gravamen a los géneros sujetos a alcabalas, cientos y millones. Vid. Ripia y Gallard (1795-1796), tomo I, pp. 21-47. 
ciales, se convierte en un nuevo proyecto de reforma fracasado al intentar ponerlo en práctica ${ }^{31}$. El propio Floridablanca reconocerá que gravar la riqueza territorial era del todo imposible y que este modesto intento había excitado las quejas de los propietarios y poderosos, alucinando con sus clamores injustos a otros vasallos inocentes y mal instruidos de lo mismo que les con$v_{\text {viene }}{ }^{32}$. La Resolución de 11 de junio de 1787 declarando exentos los bienes del clero de esta contribución ${ }^{33}$ es el reconocimiento de la imposibilidad de atentar contra la riqueza estamental ${ }^{34}$. La política llevada a cabo por Gardoqui ilustra esta tendencia al inmovilismo fiscal y el alejamiento de las tesis renovadoras tendentes a la implantación de un sistema impositivo más racional sustentado en la imposición directa. En su Exposición leída al Consejo de Estado el día 10 de agosto de $1792^{35}$, propondrá profundizar en la mejora de las rentas vigentes y en la economía de gastos de cada ministerio. El sistema tributario sigue presentando un claro predominio de los impuestos indirectos ${ }^{36}$.

No obstante, la idea de llevar a cabo la tan ansiada única contribución sigue estando presente en la mente de los escritores económicos, e incluso de altos funcionarios de la administración de rentas ${ }^{37}$. Con fecha 16 de di-

31 Artola (1982), p. 335.

32 Floridablanca (1982), p. 382. En su opinión, la actitud de los propietarios, en su intento de trasladar el peso de las contribuciones sobre los vasallos industriosos y pobres, sólo conseguiría, de llevarse a cabo, disminuir la población, el cultivo y la industria, lo que, a la postre, redundaría en perjuicio de estos mismos propietarios, cuyas rentas babrian también de disminuirse $o$ aniquilarse (Ibid., pp. 386-387).

33 «Resolución del Rey comunicada en 11 de junio de 1787, por el Excelentísimo Señor Don Pedro de Lerena a la Dirección General de Rentas, declarando lo que se ha de practicar en las dudas ocurridas sobre la contribución de los frutos civiles impuesta por el Real Decreto de 29 de junio de 1785 , y en la instrucción provisional y reglamentos aprobados por S.M. para su execución», en Ripia y Gallard (1795-1796), tomo I, pp. 47-50. En ella se declara que ninguna de las baciendas de los Eclesiásticos deben pagar, por abora, la citada imposición (Ibid., p. 48).

34 Anes (1974), p. 29. Por Decreto de 29 de agosto de 1794 se da a la contribución de frutos civiles nueva forma de arbitrio con el destino preciso de aumentar el fondo de amortización para la extinción de vales reales, creado por Decreto de 12 de enero del mismo año. En el propio Decreto se reconoce que ésta no había tenido efecto y había sido escaso su producto. «Real Decreto de 29 de agosto de 1794, por el qual se extingue la contribución de frutos civiles» y la «Instrucción que se ha de observar para la recaudación de la contribución extraordinaria sobre las rentas líquidas de los propietarios, impuesta temporalmente en las 22 Provincias de los Reynos de Castilla y León, con el objeto de aumentar el fondo creado por Real Decreto de 12 de enero de este año, para la extinción de Vales Reales», en Gallardo (1805-1808), tomo III, pp. 318-326, y Ripia y Gallard (1795-1796), tomo I, pp. 52-57.

35 Hernández Andreu (1974), p. 507.

36 Vid. Hernández Andreu (1972), p. 67.

${ }^{37}$ Entre estos últimos puede destacarse a $\mathrm{M}$. de Iparaguirre Bernardo de Quirós - contador del ejército y de las rentas reales, propios y arbitrios de Guadalajara- quien, con fecha 25 
ciembre de 1797 y por orden del Príncipe de la Paz, J. J. Caamaño y Pardo escribe un Memorial ${ }^{38}$ en el que reitera la crítica a provinciales y millones como artífices de la destrucción de la agricultura, la industria y el comercio, y la necesidad de su supresión. Caamaño propone implantar un diezmo patriótico impuesto sobre toda clase de frutos de que se acostumbra á pagar diezmo eclesiástico que recaiga sobre todos los propietarios, sin excepción alguna, evitando así que el labrador pague lo que corresponde al señor o al cura ${ }^{39}$.

El proyecto, calificado por Fontana de «descabellado» ${ }^{40}$ y por Matilla de «arbitrista e impregnado de fisiocratismo» ${ }^{41}$, tampoco llega a fructificar en la ya mítica única contribución, que tendría que esperar a la transformación política operada en Cádiz. Con la invasión francesa se pone de manifiesto la debilidad del Estado español del Antiguo Régimen y la quiebra de la Hacienda, incapaz de hacer frente a las necesidades financieras ${ }^{42}$. La urgencia del momento y la penetración de la idea de equidad contributiva llevan a las Cortes a implantar una contribución directa en sustitución del entramado impositivo heredado del Antiguo Régimen ${ }^{43}$. La polémica rentas provinciales-única contribución, resuelta en el último tercio del XVIII en favor de las primeras, se reaviva en los comienzos tan accidentados del XIX.

\section{LA CONTINUACIÓN DE UN VIEJO DEBATE: RENTAS PROVINCIALES VERSUS CONTRIBUCIÓN DIRECTA}

Durante los primeros años del siglo, son muchos los teóricos de relieve que defenderán el sistema de contribuciones directas como el que más armoniza con el sistema de libertad a implantar, defensa más patente si cabe

de marzo de 1797, remitió una exposición al Príncipe de la Paz en la que le sugería imponer una sola y única contribución. Iparaguirre (1797).

${ }^{38}$ Caamaño y Pardo (1798). La obrita consta de 29 páginas y un estado, en las que plantea sus proposiciones por medio de una serie de preguntas y respuestas, imitando un diálogo. Existe otra edición que, con ligeras variaciones, y con el título de Proyecto de una contribución para ocurrir a las urgencias del Estado dirigida al rey nuestro señor por Don..., se publica en la Imprenta de Núñez, Madrid, 1815.

${ }^{39}$ Caamaño y Pardo (1798), p. 12.

40 Fontana (1972), p. 112.

${ }^{41}$ Matilla (1947), p. 133.

${ }^{42}$ Fontana (1983a), p. 8.

${ }^{43}$ Sobre el conflicto, vid. Artola (1957), p. XXVI; Seco Serrano (1968) y Clavero (1974), p. 359. Sobre sus implicaciones en el proceso de transición, vid. dos interpretaciones de signo contrario en Fernández de Castro (1968), p. 38, y Aymes (1977), pp. 46-47. 
en los debates de Cortes. No obstante, un importante núcleo de autores niega la posibilidad de implantar un impuesto directo en sustitución del sistema de rentas vigente. Esta corriente crítica con la abolición se inicia con el Informe de Vicente Alcalá Galiano, sigue su recorrido en los debates de Cortes y en las impugnaciones de Duaso, Pinilla y Plana al Decreto de 13 de septiembre, sobre Nuevo Plan de contribuciones públicas, y culmina con los escritos de Cañedo, en la década de 1820.

El Informe de Galiano ${ }^{44}$ responde a la solicitud de F. de Saavedra, de 15 de agosto de 1809 , en la que le pide que se pronuncie acerca de la contribución equivalente a las rentas provinciales, que debían ser suprimidas por el Decreto de 7 de agosto de 1809. Alcalá Galiano redacta su Informe con toda celeridad y en su introducción escribe que sus argumentos responden más a satisfacer la petición del ministro que a su convicción de la certeza de la medida ${ }^{45}$. No obstante sentenciar que los tributos sobre los consumos no son los mas conformes á un pueblo libre, intenta desmitificar la maldad de las rentas provinciales, achacando la negativa visión que sobre ellas existe al impacto, en la teoría financiera, de los principios esgrimidos por Zavala en su Memorial.

Galiano basa su defensa en los «principios de la economía política» y arremete contra las críticas más comunes formuladas contra estas rentas: la desigualdad social de su gravamen y su negativo efecto sobre los salarios y, por ende, sobre la competencia de las manufacturas nacionales con las extranjeras. A su juicio, la reforma de 1785 corrigió estos defectos al extender los encabezamientos y gravar con mayor dureza los géneros extranjeros frente a los nacionales. Con esta doble medida, aduce, se ayudó al desarrollo de la industria nacional ${ }^{46}$. También subrayará las dificultades que plan-

44 Alcalá Galiano (1810). El informe está firmado en Sevilla con fecha de 15 de septiembre de 1809 , es decir, a un mes de distancia de la petición de Saavedra. Lo reproduce, con ligeras variaciones, Diaz de Baeza (1834), tomo I, pp. 3-89. A propósito de las ideas fiscales de Alcalá Galiano, vid., entre otros, Lasarte (1976), p. 169; Elorza (1968b), p. 76, y (1970), p. 176. Sobre su ambigüedad, Alcalá Galiano, Antonio (1955), tomo LXXXIII, p. 389. La actuación personal de Galiano fue ampliamente cuestionada. Así, en su n. 23 , de fecha 23 de febrero de 1813 , el Tribuno del Pueblo Español describe su trayectoria en términos muy elocuentes, criticando abiertamente su actuación en Bayona. El articulista lo califica de acérrimo defensor de las alca. balas, cientos $y$ millones.

45 «Informe por Dn... sobre el decreto de 11 de agosto de $1809 . .$. , en Díaz de Baeza (1834), p. 62.

46 Alcalá Galiano (1810), pp. 45-46. Fontana (1973), p. 47, sostiene que Galiano, que años atrás babia fulminado las más duras críticas contra las rentas provinciales, se manifestaba abora contra su supresión y entonaba un canto a la bondad del sistema de encabezamiento. Esta apreciación puede matizarse ya que la crítica de Galiano se refería al sistema anterior a 1785, y se dirigía, 
tearía la exacción de una contribución directa. Entre éstas destaca la imposibilidad de obtener una cantidad similar a la que proporcionaban las rentas provinciales; la problemática de la información estadística de la riqueza, condición necesaria para la distribución de un impuesto directo; y, por último, el impacto de todo cambio, singularmente, en materia tributaria, al exigirle al pueblo un cambio radical en sus costumbres ${ }^{47}$. Su propuesta tributaria se concreta en un sistema «modificado» de rentas provinciales, esto es, una contribución mixta de consumos y territorial.

Con independencia de su acogida en el momento en que se emite y su posible posterior influencia, tanto en el futuro del Decreto de 7 de agosto de $1809^{48}$, como en el desarrollo de los distintos proyectos de transformación del sistema tributario que se dan en el periodo, el Informe constituye el inicio de una cadena de escritos que se publican en los años posteriores, intentando encontrar el tributo o sistema de tributos susceptibles de sustituir a las rentas abolidas ${ }^{49}$. Como escribiera Torrente, las «luminosas ideas» sobre la Hacienda de Alcalá Galiano, aunque rebatidas por los principales campeones de las Cortes ${ }^{50}$, se verían demostradas con el tiempo y la experiencia demostraría su solidez y acierto.

En efecto, entre la multitud de folletos y papeles de todo tipo que se publican cuestionando el plan de contribución directa propuesto por el Decreto y la Instrucción de 13 de septiembre de 1813 destaca un grupo en el que se reproducen gran parte de las argumentaciones esgrimidas por V. Alcalá Galiano ${ }^{51}$. En todos ellos se critica tanto el sistema de contribu-

fundamentalmente, a su sistema de administración cuyos vicios podían evitarse, en su mayoria, con un sistema de encabezamiento. Cfr. Alcalá Galiano (1786), tomo II, p. 183.

47 Alcalá Galiano (1810), pp. 78-80.

${ }^{48}$ Hernández Andreu (1972), p. 79, atribuye la no aplicación del Decreto al seguimiento de las tesis de este Informe.

49 Vid. Artola (1975), tomo I, p. 450.

${ }^{50}$ Torrente (1835), tomo III, pp. 184-185, califica a ando su proyección de futuro.

ideas más significativas contenidas en el informe, apunios de la única contribución directa decre-

${ }^{51}$ Entre otros, un opúsculo anónimo titulado Vicios de 56 , al sacerdote José Duaso y Latre tada en 1813, atribuido por el profesor Fontana (istura gaditana (en adelante, Duaso); y un fo(Huesca, 1775-1849), diputado a Cortes en la legislatoplitano y administrador general de la milleto de Antonio Plana, contador del cabildo metropole Agravios bechos en el repartimiento de tra arzobispal, presentado bajo el significativo titulo de Agricultura de España en general: vicios inseparables de la estadística y modo de repartir aquella costacables, asimismo, el «Proyecto de Sobre estas obras, vid. Forcadell (1984), p. 239. D. Fernando VII (que Dios guarde) el intenReal Hacienda que dedica al Rey nuestro senor D. Fón Imprenta de Collado, Madrid, 1814; y la dente de Guadalaxara D. José Lopez Juana Pinilla 
ción directa como la base del reparto ${ }^{52}$. A la imposibilidad de realizar una estadística fiable que permitiese el establecimiento de una contribución directa justa se añaden apreciaciones sobre la coyuntura económica, política y social del país, que no admite cambios bruscos del sistema impositivo ${ }^{53}$. En cualquier caso, como el propio Duaso advierte, el debate entre contribuciones directas e indirectas estaba lejos de ser resuelto en favor de las primeras ${ }^{54}$.

Las argumentaciones en defensa de las contribuciones indirectas son reiterativas y parten del conocimiento de las obras de los economistas liberales. A su pago gradual, su proporcionalidad con respecto a las facultades del individuo, su ataque a los consumos y su generalidad ${ }^{55}$ se añaden dos ventajas «imaginarias» importantes: son insensibles ${ }^{56} \mathrm{y}$ tienen carácter volunta-

congreso nacional, manifestando la necesidad de establecer sobre bases sólidas el sistema general de Hacienda Pública, y de suspender por ahora los efectos de la ley de 13 de septiembre de 1813 , en que se suprimen las rentas provinciales y estancadas, y se establece una contribución directa sobre los tres ramos de riqueza territorial, industrial y comercial», Imprenta $\mathrm{Na}$ cional, Madrid, 1814. Los recoge Fontana (1976), con selección, introducción y notas complementarias.

52 El Censo de 1799, que sirvió de base a la citada contribución directa, concentró hasta tal punto las críticas que se llegó a atribuirle el fracaso del proyecto. Al igual que para los numerosos diputados que se opusieron a su utilización, para estos autores no podía establecerse un sistema de contribuciones justo utilizando un instrumento estadístico que contuviera tan graves desajustes. Así lo vería Banqueri (1821), pp. 7-8, unos años más tarde.

${ }_{33}$ Duaso (1814), p. 8, advierte de la convulsión que causaría un cambio repentino en la forma de contribuir y apoya la tesis de Canard, muy difundida en la época, sobre la bondad de los impuestos antiguos frente a los nuevos. Para este autor, el impuesto era más perjudicial por los desequilibrios que causaba que por él mismo, de ahí que sentenciara: tout vieil impôt est bon, et tout nouvel impôt est mauvais, Canard (1801).

$54 \mathrm{El}$ alcance de este juicio es evidente a tenor de las razones expuestas por San Martín (1820), a propósito de la Contribución directa de 1817.

55 Para Duaso (1814), p. 6, gravar los consumos fomenta el ahorro, evita la destrucción de la riqueza y es un medio de imposición universal. La idea también aparece en Say (1807), tomo III, p. 415, quien afirmará que si bien el impuesto de los consumos no se pagaba por los que sacaban la renta del país, le pagan todos los que traen su renta de paises extrangeros para comerselo en el propio.

${ }^{56} \mathrm{La}$ insensibilidad es la virtud más reiteradamente señalada por los defensores de las contribuciones indirectas. Así, Pinilla (1814a y 1814b) escribirá que al estar los impuestos embebidos en el precio, el consumidor es gravado de forma imperceptible, por lo que se siente menos atacado y presenta menos oposición a su contribución a las cargas públicas, dado que es difícil discernir entre contribución y precio. Para Say (1807), tomo III, p. 411, Toda contribución es una deuda, que se paga de mala gana, porque el título o el fundamento de ella, que es la protección del gobierno, es una ventaja negativa, que bace poca impresión. El gobierno es más estimable por los males de que preserva que por los bienes que procura. Mas quando se paga un impuesto sobre los géneros, no se imagina pagar la protección del gobierno la qual mueve poco, sino el precio del genero que se apetece con ansia, aunque este precio nada tenga que ver con el impuesto. El deseo del consumo se extiende basta el pago de la deuda; y se paga con gusto un valor 
rio ${ }^{57}$. Por el contrario, se aduce, las contribuciones directas atacan la riqueza del país porque recaen con mucha frecuencia sobre los capitales; su pago es excesivamente evidente; son injustas, dada la dificultad de averiguar la riqueza imponible. De otro lado, si la insensibilidad era una de las principales cualidades de las contribuciones indirectas, la contribución directa, ni puede disimularse, ni dexar de presentarse con frecuencia á nuestra fantasia ${ }^{58}$.

Pinilla apostará por la reforma administrativa del sistema vigente, basada en el encabezamiento. Plana y Duaso reivindicarán el método de los antiguos aragoneses como ya hiciera Vicente Alcalá Galiano, fundamentado en la distinción de los contribuyentes en función del tamaño de la población. Siguiendo a Steuart y ante la dificultad de encontrar un método puro de contribuciones indirectas o directas solamente, Duaso propondrá el sistema «mixto» de la contribución indirecta de las grandes ciudades, y de la directa de los pueblos inferiores por el método de Aragón ${ }^{59}$. Esta idea es la que, más tarde, propondrá Garay ${ }^{60}$ y que J. J. Banqueri defenderá ante las Cortes ${ }^{61}$. Duaso reproduce, en parte, los argumentos esgrimidos por $\mathrm{Ga}$ liano en su Informe de 1809 y, como aquél, dirá que Zabala y otros economistas del siglo último, fundados en cálculos inexactos y acomodados a su fantasia, creyeron ver en estas rentas el origen de nuestros males, opinión que llegó a hacerse general y como de moda. De ahí derivarían, a su juicio, los intentos de 1749 y 1770 , abandonados ante las dificultades y optándose por la reforma de las rentas provinciales, al considerarla más util que su extinción.

cuyo precio se juzga ser el logro de alguna comodidad (...). Say enfatiza la cuestión por el lado del Gasto, ya que, a su juicio, el beneficio que procura el Estado al realizar su acción fiscal es una idea abstracta para el contribuyente, mientras que la carga que supone la contribución se hace notar de forma concreta. De ahí puede inferirse la necesaria moderación de los tributos como el resultado de una política fiscal positiva, lo que conduce a circunscribir la intervención estatal en un espacio limitado. En definitiva, encontramos la matriz del pensamiento hacendístico liberal.

${ }^{7} \mathrm{El}$ argumento de la voluntariedad está íntimamente ligado al carácter de la necesidad de los consumos, por lo que Pinilla (1814b) llega a calificar como no contribuciones a las rentas estancadas, ya que no cargan sobre artículos de absoluta necesidad, y el consumo nace de la voluntad de los consumidores.

58 El no contar con los efectos de la opinión y de la imaginación es un gran vicio de las abs. tracciones en economia política, decía Necker. Duaso (1814), pp. 6-7. La visibilidad del pago de la contribución directa es tan evidente que Say (1807), p. 412, llega a decir que tiene todas las apariencias de un despojo arbitrario.

59 Duaso (1814), p. 57.

${ }^{60}$ Vid. Fontana (1983b), p. 171, y Lampreave (1969), p. 887.

61. Banqueri (1821), p. 3. 


\section{LA DEFENSA DEL SISTEMA DE 1785 A LA LUZ DE LOS PRINCIPIOS DE LA IMPOSICIÓN SMITHIANOS}

Ramón M. ${ }^{a}$ Cañedo y del Riego (San Tirso-Asturias, 25-11-1779, Candamo, 1837) era estudiante de Derecho en Oviedo cuando la invasión francesa, estudios que deja para presentarse voluntario al ejército. En 1811 ocupa el cargo de interventor de la Aduana de Vigo, y en 1816 el de oficial de la Contaduría de rentas provinciales, de la que llegaría a ser oficial primero. Cesante en 1823, será restituido en 1831 al empleo de oficial segundo en la Comisión Central de la Liquidación de Atrasos del Ministerio de Hacienda, y en 1834 ocupará el cargo de jefe de mesa en el Ministerio de Hacienda y secretario de S.M., con ejercicio de decretos. Cañedo, hombre a caballo no sólo entre dos siglos, sino entre una España y otra, presenta el perfil que describió Fontana del funcionario al servicio de la Hacienda y conocedor de sus expedientes. Pero, también, el de hombre ilustrado e inquieto, que le llevará a publicar en 1820 el periódico Biblioteca Económica o Anales de Agricultura, Artes y Comercio, en colaboración con la Secretaría de Hacienda.

Su dilatado paso por la Hacienda y los conocimientos adquiridos en sus años de funcionario le van a permitir acercarse a los aspectos teóricos de los distintos proyectos emprendidos y plasmarlos en varias obras. La primera de éstas data de 1814, y aunque su título, Nociones de Economía Política, parece apuntar a aspectos más generales de la teoría económica, su contenido responde a un intento de aclarar la naturaleza de las contribuciones existentes, su influencia sobre la prosperidad de la nación y los medios para restablecer la actividad económica sobre las bases de un nuevo plan de $\mathrm{Ha}$ cienda. A tal fin, compara las rentas provinciales con la contribución directa de 1813 con el objetivo de demostrar la influencia de cada sistema sobre agricultura, artes y comercio.

Después de analizar las distintas fuentes de riqueza - renta territorial (incluida la de las casas), renta o ganancias de la industria y el comercio y objetos de consumo- y las posibilidades que ofrecían de ser gravadas, propone un moderado impuesto sobre la renta territorial, por la facilidad de estimarla. Por otro lado, y ante las dificultades que planteaba conocer las ganancias del comercio y de la industria, obstáculo insalvable al proyecto de contribución única, se inclina por gravar un corto número de artículos de lujo como el vino, aguardiente, tabaco o chocolate en la primera venta, por sus nulos efectos sobre los salarios del trabajo ${ }^{62}$.

62 Cañedo (1814). Sobre la discusión clásica acerca de los impuestos indirectos, vid. O'Brien (1989), pp. 357-358. Musgrave (1990), p. 312, ha expuesto las tendencias de los 
Dos años más tarde se referiría al desfase existente entre recaudación e ingreso en el Tesoro como un mal congénito del sistema de rentas vigente y uno de sus principales vicios, señalando que de las cinco quintas partes de lo que efectivamente contribuye ó al menos debe contribuir la nación por el ramo de rentas provinciales solamente entran dos en el Tesoro ${ }^{63}$. A partir de unas estimaciones sobre el consumo personal en términos similares a las efectuadas por Zabala ${ }^{64}$, Cañedo propone un «encabezamiento forzoso» de todas las provincias donde se administraban las rentas provinciales, sin establecer excepciones de ciudades ni pueblos grandes ${ }^{65}$.

Ya en la década de 1820 , con los conocimientos más asentados como fruto de sus múltiples lecturas de autores económicos, tanto españoles como extranjeros, publica sus «Cartas económicas», en las que se planteará una tardía defensa del sistema de rentas provinciales de $1785^{66}$. Estas Cartas constituyen un auténtico manantial de información sobre la historia de la Hacienda y un pormenorizado estudio de cada una de las rentas que componían el sistema tributario de la época. Las argumentaciones vertidas en ellas, en su defensa de las rentas provinciales, tal como quedaron por los Reglamentos de 1785, reflejan una gran similitud con las líneas básicas contenidas en el Informe de V. Alcalá Galiano. Para Cañedo, con la Reforma de 1785 se consiguió el alivio de la agricultura, de las artes y del tráfico interior y el mejor sistema de impuestos de Europa ${ }^{67}$. También, como aquél, Cañedo niega que las rentas provinciales tuvieran efectos negativos sobre la riqueza de la nación e intenta desmantelar la principal acusación formulada a estas rentas: haber sido la causa de la decadencia y despoblación del reino, cir-

últimos años del siglo XVIII y principios del XIX, relativas a las posibles fuentes de riqueza susceptibles de ser objeto de gravamen.

${ }^{63}$ Cañedo (1816), p. 5.

${ }^{64}$ Fontana (1972), p. 113.

65 Cañedo (1816), p. 27.

66 Cañedo (1826). Las Cartas aparecen sin el nombre del autor, pero con las iniciales D.R.M.C. Correa Calderón (1981) cita una edición de 1820 de la misma imprenta con las iniciales R.M.C. Por su parte, Roglá de Leuw (1974) cita las cartas económicas a nombre de Ramón Cañedo, pero por una edición de 1832, en la imprenta de León Amarita. También son varios los pasajes de su Biblioteca en los que Pinilla (1840-1848) cita a Cañedo como autor de las Cartas. Concretamente en una nota al pie de la p. 156, tomo II, al referirse al origen de la renta de millones, cita la carta $7 .^{2}$ del tomo I, p. 35, en la que observa inexactitudes en los datos aportados por Cañedo. Tambien al pie de la p. 217 del mismo tomo y en p. 221 apoya sus tesis acerca del origen del quinto y millón de la nieve en la postura defendida por Cañedo en su carta IX, tomo I, p. 152.

${ }^{6}$ Un análisis detallado de la situación en que quedaron cientos, alcabala y millones después de la reforma de 1785, en Carta IV (cientos), pp. 26-65; Carta V (alcabala y cientos), pp. 26/80; Carta VI (exenciones de derechos) y Carta VII (millones), pp. 38-39. 
cunstancia que dio lugar a los sucesivos intentos de subrogación de 1749 , 1809 y $1813^{68}$.

De la misma manera que Smith habia servido para justificar la adopción de un impuesto directo durante el período constituyente, Cañedo se va a apoyar en este autor, el bombre que mas profundamente ba estudiado y conocido la bistoria económica de las naciones, para establecer los principios del sistema impositivo ideal, y de acuerdo con éstos, certificar la bondad de las rentas provinciales. Este hecho demuestra, de un lado, la vigencia de Smith en el primer cuarto del siglo XIX ${ }^{69} \mathrm{y}$, de otro, que la utilización de sus tesis no era patrimonio exclusivo de una tendencia concreta de opinión en materia fiscal. Cañedo articula su análisis en tres apartados: defensa del sistema implantado en 1785; impugnación de un sistema basado en la contribución directa; dificultad de sustituir un sistema impositivo por otro, habida cuenta de la interrelación existente entre las distintas partes que conforman el sistema económico y social.

En su opinión, el ajuste de los encabezamientos de 1785 corrigió los defectos del anterior sistema de administración, evitando la desigualdad en la exacción, con lo que se consiguió que cumpliera la máxima de hacer contribuir a todos los ciudadanos con igualdad y á proporción de sus haberes. Por otro lado, y admitiendo como cierta la crítica al sistema de rentas provinciales por lo elevado de sus derechos, sostiene que la rebaja producida por la aplicación de los reglamentos de ese mismo año lo convierte en un sistema que respeta el principio de estar compuesto por impuestos moderados $^{70}$.

El alcance del encabezamiento a la mayoría de los pueblos de la península, aduce, convertía el sistema administrativo de estas rentas en un método de facil recaudación y no beligerante con la libertad de comercio. Sólo escapaban a las reglas y soportaban la contribución indirecta en sentido estricto los que no quieren sujetarse á los ajustes y conciertos y á los traficantes forasteros que eventualmente concurren al pueblo á vender sus cosas ${ }^{71}$. De la misma forma, las únicas trabas que persistían eran las molestias y detenciones causadas por los registros y contrarregistros, y la formalidad de guías y tornaguías, indispensables en el reconocimiento de géneros y liquidación y

68 Cañedo (1826), Carta XIV, pp. 192-193.

69 Cañedo (1826), Carta XIV, p. 190, nota, recomienda el estudio de Smith, Canard, Say, Destutt-Tracy, Sismondi y Maltus (sic) para profundizar en la ciencia económica. Sobre la hegemonía de Smith en los primeros años del siglo XIX, vid. Martín Rodríguez (1989), p. 90.

${ }^{70}$ Cañedo (1826), pp. 211-212.

7 Cañedo (1826), pp. 215-216. 
cobro de derechos, en los pueblos administrados ${ }^{72}$. Por último, argüirá, la ausencia de puertas, empleados, registros y detenciones en los pueblos encabezados, permitía a los géneros nacionales circular sin intervenciones fiscales, y sólo los extranjeros eran trabados, lo que redundaba en fomento de la industria nacional ${ }^{73}$.

Esto le lleva a sentenciar que el sistema cumplía, por tanto, una de las máximas fundamentales del sistema «ideal» smithiano: recaudación sencilla $y$ de pocos gastos y que coarte la libertad del comercio con las menos trabas posibles. Pero no quedaban ahí las alabanzas: con la rebaja de derechos a los productos agrícolas e industriales y el aumento de los derechos de entrada al país para evitar la competencia de los géneros extranjeros, realizada en 1785, el sistema tributario se constituía en elemento de progreso, al gravar cada artículo en función del grado de desarrollo ó decadencia que presente. Su conclusión es que las rentas provinciales, si bien pueden ser todavia susceptibles de alguna mejora accidental, no son tan malas en la esencia como nos las ban querido pintar algunos antiguos y modernos escritores ${ }^{74}$.

Por el contrario, subrayará, si el sistema se sustentara en una contribución única y excluyera los impuestos sobre el consumo, la carga gravitaría sobre las tres bases de la riqueza - territorial, industrial y comercial-, aumentando la incertidumbre y desigualdad de las cuotas. A su juicio, la contribución directa, entendida como modelo ideal, cumplía todos los principios exigibles a un buen sistema impositivo: justicia, igualdad y generalidad, y, desde el punto de vista administrativo, garantizaba una recaudación sencilla y económica, que evitaba el fraude y ponía pocos obstáculos al comercio e industria ${ }^{75}$.

El problema, escribirá Cañedo, surgía al descender al terreno de la realidad. Este modelo ideal se tornaba una quimera en un país sin una buena estadística y cuya riqueza no ofreciera un alto nivel de desarrollo. El ejemplo que ofrece en apoyo de sus tesis es la situación en que se encontraba España cuando se intentó implantar la contribución directa decretada el 13 de septiembre de 1813. A los autores del proyecto, dirá, se les escapó un aspecto fundamental, la facilidad de su cobranza. No vieron que la masa común del pueblo prefiere siempre, y le es menos sensible pagar más, baciéndo. lo en partes sucesivas y pequeñas, que contribuir con menos de una sola vez:

72 Cañedo (1826), p. 217.

73 Cañedo (1826), p. 216.

${ }^{74}$ Cañedo (1826), p. 218.

75 Cañedo (1826), Carta XIV, pp. 187-188. 
porque cuando tiene pocas facultades le es más difícil el proporcionar los cupos sin malvender sus cosas, ó cercenar acaso su pequeño capital productivo, acabando por arruinarle al cabo de cierto tiempo.

Cañedo encara la problemática de la sustitución del sistema tributario desde una doble perspectiva: su impacto sobre el total de la actividad económica, dados los puntos de contacto entre el sistema de Hacienda y los demás ramos de la administración ${ }^{76}$, y el vacío recaudatorio subsiguiente con su efecto transmisor sobre el total de la economía: la falta de ingresos conducía al atraso en el pago a las personas dependientes del gobierno y la disminución de los salarios de las clases útiles.

\section{CONSIDERACIONES FINALES}

La implantación de un impuesto directo en la España del siglo XVIII es un proyecto irrealizable, dado que a las dificultades técnicas se unía la resistencia de los estamentos afectados. La reforma de Lerena es, desde esta perspectiva, la adecuada al marco económico, social y político en que se lleva a cabo, si no se quería alterarlo. Durante las Cortes de Cádiz se proyecta implantar una contribución directa sobre la riqueza, aprovechando el clima de renovación que todo lo inunda. El proyecto se concreta en el Decreto de 13 de septiembre de 1813 , sobre «Nuevo plan de contribuciones públicas», pero su vida es muy corta. La llegada de Fernando VII significa el fin de toda la obra legislativa de las Cortes gaditanas y se retorna al sistema tributario de 1808 .

No obstante, la polémica rentas provinciales-única contribución sigue vigente en la primera mitad del siglo XIX. Infinidad de escritos intentan defender, con mayor o menor fortuna, la bondad de uno u otro sistema. Ramón M. ${ }^{a}$ Cañedo se alineará en la corriente iniciada por V. Alcalá Galiano y apostará por un sistema impositivo con predominio de impuestos indirectos. Apoyándose teóricamente en Smith, intentará adecuar sus principios tributarios al sistema de rentas reformado en 1785. Partiendo de la hipótesis de que el impuesto indirecto es el que más se adapta a las condiciones sociales y materiales de la España de la época, y de que el impuesto directo es, en el plano teórico, el más justo, pero una quimera el in-

${ }^{76}$ En su opinión, en la sociedad como en la naturaleza todo está relacionado, todo es una cadena de intereses recíprocos y el sistema de Hacienda de un Estado forma como el primer anillo de esta gran cadena, el cual si se rompe, o sufre alteraciones, destruye o desconcierta toda su armonia. Cañedo (1826), Carta II, pp. 22-23. 
tentar convertirlo en realidad, Cañedo se va a inclinar por el sistema modificado de rentas provinciales.

\section{BIBLIOGRAFÍA}

AlCalá Galiano, A. (1955): «Memorias», en Obras escogidas, Madrid, B.A.E., Atlas, tomo LXXXIII.

ALCALA Galiano, V. (1810): Informe por Don... sobre el decreto de 11 de agosto de 1809. En que se mandaron suprimir las rentas provinciales luego que se subrogasen en otras equivalentes, Valencia, Imprenta de $D$. Benito Monfort.

- (1786): «Sobre los nuevos impuestos», en Actas y Memorias de la Real Sociedad Económica de la provincia de Segovia, Imprenta de D. Antonio Espinosa, Segovia, 1786, tomo II.

ANES, G. (1974): «La contribución de frutos civiles entre los proyectos de reforma tributaria en la España del siglo XVIII», Hacienda Pública Española, n. ${ }^{\circ} 27$, pp. 31-45.

ARROYAL, L. DE (1971): Cartas económicas dirigidas al Conde de Lerena, 1787-1794, edición a cargo de J. Caso González, Universidad de Oviedo.

ARTOLA, M. (1957): Memorias de tiempos de Fernando VII, Madrid, Biblioteca de Autores Españoles, Atlas, tomo XCVII.

- (1975): Los origenes de la España contemporánea, Madrid, Instituto de Estudios Políticos, 2 vols.

- (1982): La Hacienda del Antiguo Régimen, Madrid, Alianza/Banco de España.

- (1986): La Hacienda del siglo XIX. Progresistas y moderados, Madrid, Alianza.

AYMES, R. (1977): «La Guerra de la Independencia (1808-1814) y las postrimerías del Antiguo Régimen: ¿Sucesión forzosa o sucesión abierta?», en M. Tuñón de Lara, A. Gil Novales y otros: Crisis del Antiguo Régimen e industrialización en la España del siglo XIX, VII coloquio de Pau. De la Crisis del Antiguo Régimen al franquismo, Madrid, Cuadernos para el Diálogo.

BANQUERI, J. J. (1821): Observaciones presentadas a las Cortes de 1821 sobre un plan general de Hacienda por el diputado de las mismas..., Madrid, Oficina de Martínez Dávila.

CAAMAÑO Y PARDO, J. J. (1798): Substitución a las rentas provinciales con la única y universal contribución, que por orden del Excelentísimo Señor Príncipe de la Paz, su fecha 16 de diciembre de 1797 ba formado Don..., Madrid, Imprenta de Sancha.

CABARRús, F. DE (s.f.): Cartas sobre los obstáculos que la naturaleza, la opinión y las leyes oponen a la felicidad pública, Imprenta Vda. de D. Agustín Roca.

CANARD, J. (1801): Principes d'économie politique, París, Buisson.

CAÑEDO, R. M. (1814): Nociones de Economía Política, Madrid, Imprenta de D. Miguel de Burgos.

- (1816): Ensayo crítico sobre la naturaleza de las rentas provinciales y necesidad de subrogarlas por un sistema general de encabezamiento dispuesto en forma de exposición a S.M..., Madrid, Imprenta de Burgos. 
CAÑEDO, R. M. (1826): Cartas económicas escritas por un amigo a otro, o sea, tratado teórico-práctico elemental sobre la naturaleza de cada una de las rentas de la corona y de su régimen administrativo, con arreglo a los últimos decretos e instrucciones sobre la materia, Madrid, Imprenta de D. Pedro Sanz.

Carrera PUJAL, J. (1943-47): Historia de la economia española, Barcelona, Bosch, tomo IV.

Clavero, B. (1974): Mayorazgo. Propiedad feudal en Castilla, 1369-1836, Madrid, Siglo XXI.

Colección de los Decretos y Ordenes que ban expedido las Cortes Generales y Extraordinarias desde su instalación (1813): Cádiz, Imprenta Nacional, tomo IV.

COMín, F. (1990): Las cuentas de la Hacienda preliberal en España (1800-1855), Madrid, Banco de España.

(1996): Historia de la Hacienda Pública, II. España (1800-1995), Barcelona, Crítica.

CORREA CALDERÓN, E. (1981): Registro de arbitristas, economistas y reformadores españoles (1500-1936). Catálogo de impresos y manuscritos, Madrid, Fundación Universitaria Española.

Decretos del Rey D. Fernando VII (1818): Madrid, Imprenta Real, tomo I, pp. 84-89.

Decretos, órdenes y reglamentos expedidos por la Regencia del reino desde su instalación (1823): Barcelona, Brusi.

DIAZ DE BAEZA, D. (1834): Sistema de Hacienda controvertido en España desde el año de 1809 basta el de 1823, Madrid, Imprenta de D. Norberto Moreno, tomo I.

DuASO, J. (1814): Vicios de la única contribución directa decretada en 1813, Madrid, Imprenta de Ibarra.

ElorzA, A. (1968a): «Los comienzos de una hacienda liberal en España: Cabarrús», Revista de Derecho Financiero y Hacienda Pública, n. ${ }^{\circ} 75$, pp. 565-578.

— (1968b): «El liberalismo económico de Vicente Alcalá Galiano», Moneda y Crédito, n. ${ }^{\circ} 106$, pp. 91-111.

ESTAPE, F. (1971): La reforma tributaria de 1845, Madrid, Instituto de Estudios Fiscales.

FERNÁNDEZ de CASTRO, I. (1968): De las Cortes de Cádiz al plan de desarrollo, 18081966. Ensayo de interpretación política de la España contemporánea, Madrid, Ruedo Ibérico.

FLORIDABLANCA, CONDE DE (1784): Dictamen del señor... sobre el modo de aumentar las rentas provinciales (15-5-1784), Archivo Histórico Nacional, Estado, leg. 238 , núm. 2.

- (1982): «Instrucción Reservada a la Junta de Estado, creada formalmente por mi decreto de este día, 8 de julio de 1787», en Escritos políticos, la Instrucción y el Memorial, Academia de Alfonso X el Sabio, Murcia.

FONTANA, J. (1972): «La supervivencia del mito de la única contribución. Noticia de algunos arbitristas españoles de comienzos del XIX», Hacienda Pública Española, n. ${ }^{\circ} 17$, pp. 111-119.

- (1973): Hacienda y Estado en la crisis final del Antiguo Régimen español (18231833), Madrid, Instituto de Estudios Fiscales.

—_ (1976): «José López-Juana Pinilla, una gran figura de la Hacienda española del siglo XIX», Hacienda Pública Española, n. ${ }^{\circ} 38$, pp. 93-100. 
FonTANA, J. (1980): La Hacienda en la historia de España. 1700-1931, Madrid, Instituto de Estudios Fiscales.

- (1983a): La crisis del Antiguo Régimen. 1808-1833, Barcelona, Crítica. (1983b): La quiebra de la monarquía absoluta (1814-1820), Barcelona, Ariel. (1987): «El alimento del Estado. Política y Hacienda en el "despotismo ilustrado" ", Hacienda Pública Española, n. ${ }^{\text {os }} 108-109$, pp. 157-168.

(1990): «Modernización y progreso: política y hacienda del despotismo ilustrado», en E. Fernández de Pinedo (ed.): Haciendas forales y Hacienda real. Homenaje a D. Miguel Artola y D. Felipe Ruiz Martín, Bilbao, Universidad del País Vasco.

FORCADELL ÁlVAREZ, C. (1984): «El sistema fiscal aragonés: de la única contribución a los desajustes y agravios tributarios tras la guerra de la independencia», en $\mathrm{M}$. Artola y L. M. Bilbao (eds.): Estudios de Hacienda. De Ensenada a Mon, Madrid, Instituto de Estudios Fiscales, Monografía, n. ${ }^{\circ} 31$.

FUENTES QUINTANA, E. (1964): «El impuesto sobre el volumen de ventas: perspectivas de una idea fiscal española», Anales de economia española, 2." época, n. ${ }^{\circ} 5$, pp. 1-160.

- (1990): Las reformas tributarias en España. Teoria, bistoria y propuestas, Barcelona, Crítica. Edición al cuidado de Francisco Comín.

GallaRDO, F. (1805-1808): Origen, progresos y estado de las rentas de la Corona de España, su gobierno y administración. Por Don..., oficial de la Secretaria de Estado y Despacho Universal de Hacienda de España, del Consejo de S.M., su secretario con exercicio de Decretos, Madrid, Imprenta Real.

GARCIA-CUENCA ARIATI, T. (1991): «El sistema impositivo y las rentas generales o de Aduanas en España en el siglo XVIII», Hacienda Pública Española, Monografías, n. ${ }^{\circ}$, pp. 59-74.

(1990): «Algunas consideraciones sobre la tributación en el reinado de Carlos III», Hacienda Pública Española, Monografías, n. ${ }^{\circ} 2$, pp. $27-34$.

GERLOFF, W. (1961): «Doctrina de la economía tributaria», en W. Gerloff y F. Neumark (drs.): Tratado de finanzas, Buenos Aires, El Ateneo, tomo II.

HERNÁNDEZ ANDREU, J. (1993): «Vicente Alcalá Galiano, los Frutos Civiles y la influencia smithiana», Revista de Historia Económica, año XI, n. ${ }^{\circ} 3$, pp. 647-654. (1974): «La Exposición de Diego Gardoqui de 13 de diciembre de 1793: un proyecto de arbitrios extraordinarios», Revista de Derecho Financiero y Hacienda Pública, vol. XXIV, n. ${ }^{\circ} 110$.

(1972): «Evolución histórica de la contribución directa en España desde 1700 a 1814», Revista de Economía Política, n. ${ }^{\circ} 61$.

IPARAGUIRRE BERNARDO DE QUIRÓ, M. DE (1797): Exposición al Príncipe de la Paz manifestándole sus ideas para el fomento de la agricultura y aumento de la $\mathrm{Ha}$ cienda, Aranjuez, 1797. Archivo Histórico Nacional, Hacienda, leg. 2.928, n. 75.

LAMPREAVE, J. (1969): «1813 y 1817: dos intentos de una contribución directa», Revista de Derecho Financiero y Hacienda Pública, vol. XIX, n. 83.

LASARTE, J. (1976): Economía y Hacienda al final del Antiguo Régimen. Dos estudios, Madrid, Instituto de Estudios Fiscales.

LEMEUNIER, G. (1989): «Hacienda real y poderes locales en la Castilla del Antiguo Régimen: las enajenaciones de la corona», en C. M. Cremades (ed.): Estado y fiscalidad en el Antiguo Régimen, Universidad de Murcia. 
LERENA, CONDE DE (1845): Descripción de todas las rentas del Estado de España dentro de la Peninsula desde la creación de ellas, presentada por un informe al Señor Rey Don Carlos IV por el ministro de Hacienda Don..., Madrid, Imprenta de D. Eusebio Aguado.

LlomBaRT, V. (1994): «La política económica de Carlos III. ¿'Fiscalismo, cosmética o estímulo al crecimiento?», Revista de Historia Económica, año XII, n. ${ }^{\circ}$, pp. 11-39.

LÓPEZ CASTELLANO, F. (1995): Liberalismo económico y reforma fiscal. La contribución directa de 1813, Granada, Universidad de Granada/Fundación Caja de Granada.

LÓPEZ-JuANa Pinilla, J. (1814a): Proyecto de Real Hacienda que dedica al Rey nuestro señor D. Fernando VII (que Dios guarde) el intendente de Guadalaxara D. José López Juana Pinilla, Madrid, Imprenta de Collado.

(1814b): Exposición que el intendente de Guadalaxara D. José López Juana Pinilla dirige al augusto congreso nacional, manifestando la necesidad de establecer sobre bases sólidas el sistema general de Hacienda Pública, y de suspender por abora los efectos de la ley de 13 de septiembre de 1813, en que se suprimen las rentas provinciales y estancadas, y se establece una contribución directa sobre los tres ramos de riqueza territorial, industrial y comercial, Madrid, Imprenta Nacional.

(1840-1848): Biblioteca de Hacienda de España dispuesta por el Ilmo. Sr... Ministro jubilado del suprimido Consejo Real de España e Indias y Senador del reino, continuada por Don Domingo López de Castro y Pinilla, Madrid, D. E. Aguado.

MARTín RoDríguez, M. (1989a): «La institucionalización de los estudios de economía política en la universidad española (1776-1857)», Revista de Historia Económica, núm. 2 suplemento, pp. 89-92.

(1989b): «La Institucionalización de los Estudios de Economía Política en la Universidad Española (1784-1857)», estudio introductorio a la obra del Marqués de Valle Santoro, Elementos de Economía Política con aplicación particular a España, Madrid, Instituto de Estudios Fiscales.

Matilla TASCÓN, A. (1947): La única contribución y el catastro de Ensenada, Madrid, Servicio de Estudios de la Inspección General del Ministerio de Hacienda.

MORAL RUIz, J. (1990): Memoria sobre las rentas püblicas y balanza comercial de España (1789-1790), Madrid, Instituto de Estudios Fiscales.

Musgrave, R. A. (1990): «Una breve historia de la doctrina fiscal», Hacienda Pública Española, n. ${ }^{\circ} 115$, pp. 299-334.

O'BRIEN, D. P. (1989): Los economistas clásicos, Madrid, Alianza.

PIEPER, R.: La Real Hacienda bajo Fernando VI y Carlos III (1753-1788), Madrid, Instituto de Estudios Fiscales.

Plana, A: (1820): Agravios bechos en el repartimiento de la contribución directa de Aragón en especial y a toda la agricultura de España en general: vicios inseparables de la estadística y modo de repartir aquella contribución más facil y equitativamente, Zaragoza, Mariano Miedes.

RIPIA, J. DE LA, y GALLARD, D. (1795-1796): Práctica de la administración y cobranza de las Rentas Reales y visita de los ministros que se ocupan de ellas, Madrid.

ROGLA DE LEUW, J. (1974): «Catálogo bibliográfico de autores españoles del siglo XIX», Hacienda Pública Española, n. ${ }^{\circ} 27$, pp. 253-276, y 28, pp. 227-334. 
SAN MARTIN, D. DE (1820): Tratado breve de contribuciones, en que se babla de las directas y de las indirectas y se demuestra con claridad qué género de imposiciones es el más correcto a la nación española, Madrid, Imprenta de D. Fermín de Villalpando.

SAY, J. B. (1807): Tratado de economía política o exposición simple del modo como se forman, distribuyen y consumen las riquezas, Madrid, Gómez Fuentenebro y Cía., 3 vols.

SECo SERrano, C. (1968): «El reinado de Fernando VII en el primer ciclo de la Revolución Contemporánea», introducción a M. Artola: «La España de Fernando VII», en Menéndez Pidal (dtor.): Historia de España, Madrid, Espasa Calpe, tomo XXVI.

SMITH, A. (1794): Investigación sobre la naturaleza y causas de la riqueza de las naciones, Valladolid, Oficina de Vda. e Hijos de Santander. Traducción y notas de A. Ortiz, 4 vols.

TedDE DE LORCA, P. (1988): El banco de San Carlos (1782-1829), Madrid, Banco de España/Alianza Editorial.

Torrente, M. (1835): Revista General de Economía Política, La Habana, Imprenta de Jordán, 3 vols.

Tribuno del Pueblo Español (El) (1813): n. $.^{\circ} 23,23-2-1813$.

ZAFRA, J. (1990): «Una aproximación al estudio de la "presión fiscal” en el reinado de Carlos III», Hacienda Pública Española, n." 2, pp. 35-46. 